\title{
LOS CABARETS PROHIBIDOS Y LA AUTORIDAD EN GUADALAJARA, JALISCO, MÉXICO
}

\author{
BANNED CABARETS AND AUTHORITY IN GUADALAJARA, \\ JALISCO, MÉXICO
}

\author{
Bogar Escobar Hernández*
}

\begin{abstract}
El trabajo analiza la actuación de la estructura de gobierno municipal y estatal de Guadalajara en relación con la extinta actividad de los cabarets citadinos, mismos que se ubicaron de manera predominante en el antiguo barrio de San Juan de Dios. Tal actividad propició en el imaginario colectivo la asociación -reiterada con el transcurso del tiempo- del barrio con lo peligroso e inseguro. Se desarrolla una particularidad que implicó la asignación de una alteridad desacreditada para los habitantes de este ámbito urbano, a partir de la cual, se construyó una diferenciación que los desfavorecía respecto de la identidad tapatía conservadora y moralista. Esa dinámica, finalmente incidió en la desaparición de los cabarets asentados en San Juan de Dios.
\end{abstract}

Palabras claves: Cabaret, ludismo, poder, intolerancia, discurso.

This paper focuses on the performance analysis of the structure of municipal and state government in the case of Guadalajara in relation to the former city dwellers activity cabarets, same as predominantly located in the old district of San Juan de God. This situation led in the collective imagination, the association -settled with the course of time-neighborhood with unsafe. A special assignment involving a discredited otherness for the inhabitants of this urban area, from which, was built a disfavoured differentiation respect the identity tapatía conservative and moralistic. That dynamic, eventually influenced in the disappearance of cabarets settled in San Juan de Dios.

Key words: Cabaret, playfulness, power, intolerance, speech.

\section{Introducción}

El interés del presente $\operatorname{artículo}^{1}$ se orienta al análisis de un componente nodal en las manifestaciones lúdicas de la población de Guadalajara, a partir de los rasgos que definieron el particular microcosmos urbano generado en torno a los cabarets ${ }^{2}$ de la ciudad, en el contexto de las décadas de los sesenta y setenta, periodo en el que alcanzaron su mayor auge (Ramos, 2005:138). Tomando como eje nodal la significación social que alcanzó el negocio del cabaret y la relación de tolerancia-conflicto que mantuvo con la autoridad municipal, la cual finalmente derivó en una radicalización de la reglamentación pública que afectaría el funcionamiento de ese tipo de establecimientos, particularmente en el barrio de San Juan de Dios.

En los cabarets se ofertaba la forma de entretenimiento conocida como "variedad", en la cual, como su nombre lo indica, se presentaban distintos tipos de personas que incluían a magos, cómicos y cantantes, si bien, el espectáculo principal lo constituían las vedettes, quienes presentaban un espectáculo compuesto generalmente de baile y canto. Asimismo, en un plano más o menos informal, en dichos establecimientos laboraban mujeres que bailaban con los clientes a cambio de fichas que les eran remuneradas económicamente por el propietario, las cuales tenían la opción de ejercer o no el llamado oficio más antiguo del mundo (Vizcarra, 2009:33, 34).

La variedad se caracterizaba por la notable riqueza de sus manifestaciones, mismas que correspondían a los gustos populares de la época. Si bien, no todos los lugares presentaban dicha variedad, limitándose algunos a presentar un espectáculo musical con grupos que tocaban en vivo, e incluso los había que solamente disponían de una rockola como oferta de diversión ${ }^{3}$.

La existencia de los cabarets como parte sobresaliente de la vida nocturna tapatía en la época pone de relieve la importancia social que alcanzó dicha opción lúdica, en una población en la que todavía predominaba un perfil sociocultural de tipo provincial, en donde las opciones de diversión existentes se convertían en un medio esencial de distensión

* Universidad de Guadalajara, Departamento de Geografía. Guadalajara, México. Correo electrónico: bescobar71@ yahoo.com.mx 
social -mediante el desahogo de las presiones o insatisfacciones de la realidad cotidiana-, al tiempo que favorecía la interacción social, sobre todo de los estratos medio y popular (Gómez y Gil, 2008:15).

Considero conveniente hacer una precisión respecto de la temática descrita. Una buena parte de los estudios realizados en torno a la ciudad de Guadalajara privilegian sobre todo aspectos políticos, económicos, demográficos o culturales, en los que destacan las expresiones artísticas, como la música, la pintura, la escultura, o la arquitectura, así como las de tipo folclórico, en este último caso se parte de una iconografía simbólica en la que se retoman el tequila, el mariachi y la charrería, como los ejes de un paradigma tradicional del que se nutre la identidad tapatía, misma que llega a adquirir una proyección nacional.

Una vez revisados los principales acervos bibliográficos de la ciudad se localizó un solo material exclusivamente alusivo al tema, un artículo publicado por Víctor Ramos Willchis, "Los cabaretes de Guadalajara", si bien, tiene la limitante de que se trata de un estudio esencialmente descriptivo, lo cual deja pendiente la elaboración de un estudio sustentado en un mayor análisis e interpretación de los eventos reseñados. Otros escritos solamente abordan el tópico de los cabarets de manera colateral o parcial, dado que tienen un objeto de interés principal distinto, o bien, elaboran sus escritos desde una perspectiva multitemática (Medina, 1999; Vizcarra, 2009; Gómez Sustaita, 2000). Es claro pues, que dicho tópico no ha sido un tema recurrente en los estudios académicos, en lo cual pareciera que se ha considerado que el mismo carece de la relevancia que justifique su estudio.

En mi caso, lo he elegido precisamente como base de la presente exposición al considerar que en una reflexión sobre el comportamiento social, no existe ninguna acción humana que no sea susceptible de ser utilizada como dato empírico que guie la interpretación de un universo de estudio dado a partir de que este ha sido delimitado con precisión. ${ }^{4}$ Desde ello, inicio de la noción de que son las actividades humanas informales que tienen lugar en el tiempo destinado al ocio, las que nos permiten percibir los comportamientos más espontáneos y auténticos del ser humano, generalmente constreñido por los diferentes controles sociales que norman la organización social organizada de manera imperativa y coercitiva al margen de la voluntad personal (Durkheim, 2000:23, 24). Dicha imposición derivada del aparato de gobierno implica, en contraparte, que este deberá procurar una conducción social tendiente a la creación de "nuevos y más elevados tipos de civilización" (Gramsci, 2002:75). El tiempo de diversión, el ocio no pertenecen a la vida prescriptiva ordinaria, constituye más propiamente un escape que permite acceder a un ámbito temporal de actividad que tiene una lógica particular (Huizinga, 1943:24), de ahí que su principal rasgo sea la liberación que proporciona al individuo. En consecuencia, la actividad lúdica resulta indispensable a nivel personal porque satisface requerimientos biológicos, y en su dimensión social lo es también dada su significación, lo que confiere a la diversión una función cultural al satisfacer ideales de expresión y convivencia (Huizinga, op. cit.:25).

Ese requerimiento fue evidente en la Guadalajara provincial que paulatinamente experimentó un proceso de metropolización, especialmente sensible desde la década de los cuarenta, caracterizado por la concentración de actividades económicas que incentivaron la migración de población proveniente del sector rural a la ciudad, con la expectativa de mejorar sus condiciones de vida (González, 1988:142; Ramírez y Safa, 2009:78). Posteriormente, en la década de los sesenta, era ya evidente que, desde una dimensión colectiva, tal desplazamiento demográfico había propiciado en la capital jalisciense un efecto contraintuitivo o perverso no deseado ni esperado (Crozier y Friedberg, 1990:14), a saber, el incremento de la conflictividad en la interacción social. Conflictividad que paulatinamente se traduciría en mayores niveles de inseguridad, contaminación ambiental, escasez de agua y congestionamientos viales (Ramírez y Safa, op . cit.:78). Una característica de toda ciudad, al ser esta "el punto de máxima tensión de todo el sistema social" debido a la exacerbada división del trabajo, la interdependencia de funciones y la contraposición de intereses que alberga (Signorelli,1999:37).

Dicha conflictividad va aparejada a todo crecimiento urbano excesivo puesto que implica "la necesidad de proporcionar cada año aún más viviendas y toda clase de servicios públicos, y de generar nuevos empleos, así como por el gran aumento de "zonas de miseria" en sus periferias, que, muchas veces, implican muy serios problemas de sanidad ambiental (por falta de servicios de agua y drenaje, al menos en sus etapas iniciales) o, incluso, el extremo de invasiones de tierras y hasta conflictos violentos" (Arroyo, 1986:17). No es de 
extrañar entonces, considerando la trascendencia tanto a nivel individual como colectivo del factor lúdico como medio de liberación de tensiones y de compensación, ante las constricciones normativas y la creciente conflictividad citadina, que los cabarets tapatíos se constituyeran en una oferta de diversión sumamente en boga entre el público masculino que era el que asistía mayoritariamente a los mismos, a pesar de las críticas de que eran objeto este tipo de establecimientos (Vizcarra, op. cit.: 32).

\section{Estigma y significacióan social}

Como se ha mencionado, la mayor parte de la oferta de cabarets se ubicaba en el barrio de San Juan de Dios, uno de los más tradicionales y antiguos de la ciudad. Si bien existían también otros cabarets localizados en el centro de la ciudad. En toda la ciudad llegaron a prestar sus servicios hasta 65 cabarets, de los cuales 42 se localizaban en San Juan de Dios (Ramos Willchis, op. cit::125, 138), lo que convertía a esta popular zona en el núcleo principal del divertimiento nocturno. Entre dichos establecimientos se encontraban El Afrocasino, El Bohemio, El Can-Can, El Casbah, El Copacabana, El Dandy, El Nopal, El Sarape, El París de Noche, La Tarara, El Tenampa y el 1-2-3 (Gómez Sustaita, op. cit.:142, 217)

El barrio de San Juan de Dios se localiza en la zona oriente de la calzada Independencia, eje vial construido sobre lo que fuera el río Guadalajara, luego llamado San Juan de Dios, y que divide espacialmente en dos a la ciudad (Vázquez, 1992:40). Si bien, como es sabido por quienes han habitado en ella o conocen la ciudad, dicha división no es exclusivamente de índole espacial, corresponde también a una distinción social, en tanto que, en general, la población de mejores ingresos vive del lado poniente de la calzada, la "gente conocida", mientras que en el lado oriente se establece la gente de ingresos más modestos, "los primos de nadie". Daniel Vázquez, uno de los urbanistas con mayor conocimiento del tema, explicaba esta situación en los siguientes términos,

Las ciudades del occidente y en especial Guadalajara, no fueron instaladas sobre, sino al lado, de los asentamientos indígenas. Tal vez porque no había por estos rumbos ni poblaciones significativas, ni civilización importante, ni poder organizado. Por esta característica, Guadalajara expresó en su ámbito y mentalidad una cierta segregación espacial que conserva, acentuada hasta nuestros días (op. cit.:40).

En esa lógica de segregación, San Juan de Dios, además del rasgo de ser uno de los barrios más populares y populosos, adquirió el estigma social de ser un espacio frecuente de riñas y vicios, lugar de operaciones de asaltantes y estafadores (Gómez y Gil, op. cit.: 5, 20). Ese perfil lo ubicó en el imaginario colectivo como un sitio inseguro que se encontraba dentro de la "geografía del crimen y de los bajos fondos", la cual se definía por la localización física y social de la población de delincuentes, las constantes manifestaciones de violencia, su designación como parte de los bajos fondos en la nota roja periodística, y el uso de una cultura popular marginal considerada inmoral por el sector dominante. En ese sentido, el Oriente de Guadalajara, en general, y el área de San Juan de Dios, en particular, se concebían como referentes de la suciedad física y moral, en oposición al Poniente, en el que se localizaba lo limpio y aceptable, el espacio seguro "desde el punto de vista de la élite y de los propios sectores que allí vivían" (Vázquez, 1985:59). En esa estigmatización no habían sido ajenas las políticas oficiales, al decretar en 1895 que fuera en San Juan en donde se estableciera formalmente la zona roja, como una medida de aminorar la molestia que provocaba la presencia de dicho sector poblacional, "comprensible desde la dicotomía poniente-oriente, es decir, a partir de una perspectiva geográfica y de clase $[. .$.$] construyó un$ imaginario social soportado por una clara orientación moralista de tipo victoriano [...] que lo dibujaba y complementaba con la idea de lo indomesticable, de lo sórdido" (Trujillo, 2002:67, 68).

No obstante ser objeto de censura y desdoro, el barrio se convirtió, al mismo tiempo, en un núcleo de atracción lúdica que concentraba distintas ofertas de diversión y convivencia. En las décadas de los sesenta y setenta, San Juan de Dios fue el lugar más frecuentado para hacer uso del tiempo de ocio. Además de las cantinas y cabarets existentes en la zona, dentro de su zona de demarcación o de influencia se localizaban el Coliseo Olímpico, la plaza de toros El Progreso, la plaza de los mariachis y la Arena Coliseo, con funciones de box y lucha libre, así como varios cines, El Alameda, El Avenida, El Metropolitan, El Park, El Juárez y el Orfeón (Gómez y Gil, op. cit.:12, 14, 15). Estos puntos de reunión eran ampliamente aprovechadas por los diferentes sectores sociales citadinos, 


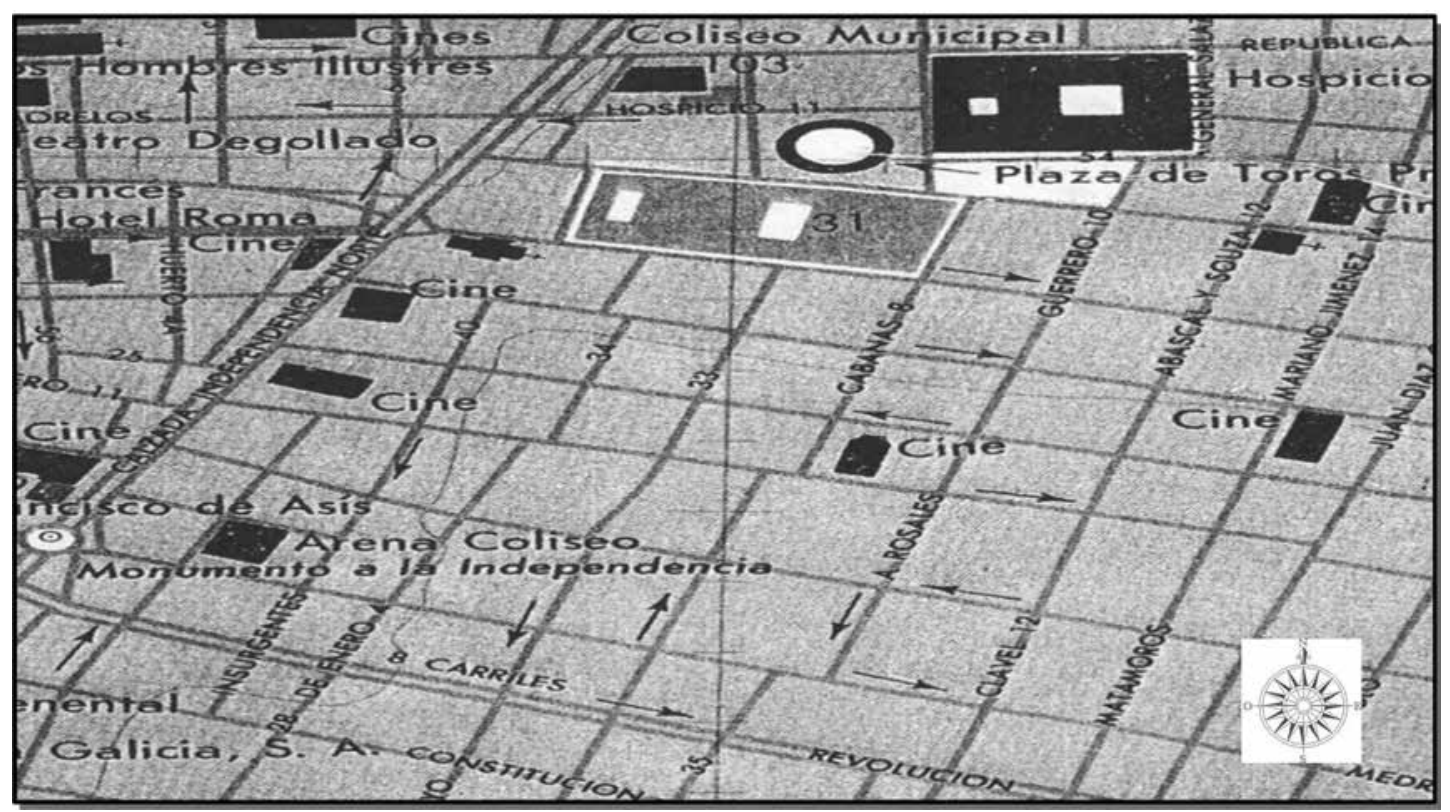

Mapa del barrio de San Juan de Dios. Delimitación: Calzada Independencia norte (poniente), República (norte), Av. Revolución (sur), Antonio Rosales (oriente). Fuente: Secretaria de Programación y Presupuesto: Coordinación General de los Servicios Nacionales de Estadística, Geografía y Estadística, Guadalajara 4, CIGUA, Ej. 1T. 4, 1970.

en lo cual fue muy favorable, y en cierta manera inductivo, el establecimiento de la jornada laboral de ocho horas -con el consecuente incremento de tiempo libre- y la estabilidad económica que se experimentaba a nivel local y nacional (Gómez Sustaita, op. cit.:144), factores cuya combinación produjo el caldo de cultivo propicio para el fomento y auge de las actividades lúdicas citadinas.

En ese medio, la oferta específica de los cabarets tenía características particulares que la distinguían del resto. En primer término destacaba el horario de funcionamiento, el cual si bien era variable, en general los establecimientos abrían a las 6 o 7 p.m. y el cierre se daba alrededor de las 4 a.m. del día siguiente, pero se podía llegar a prolongar el servicio hasta más tarde en aquellos casos en que la variedad se presentara en las primeras horas de la mañana siguiente o si todavía había clientela con dinero para seguir su consumo ${ }^{5}$. La variedad se presentaba en diferentes horarios de acuerdo a lo establecido por cada cabaret, manejando un intervalo que oscilaba entre las 10:30 p.m. y las 4:00 a.m. ${ }^{6}$. Lo que implicaba que en el microcosmos urbano del cabaret se manejara un horario opuesto al ritmo social normal de las actividades cotidianas, al funcionar en un espacio de tiempo que la mayor parte de la población destinaba para dormir.
La particularidad del horario en los cabarets, era congruente con la naturaleza disruptiva del cabaret, otro de sus rasgos esenciales. Al tratarse de espacios en los que se tendía, vía los efectos relajantes de la música, al consumo de alcohol y al ambiente festivo predominante, a manifestar lo que se puede conceptuar como una acción transparente, es decir, un comportamiento que refleja de manera más fidedigna el comportamiento espontaneo y auténtico de un individuo. En una especie de catarsis que permitía desmarcarse de las constricciones impuestas socialmente por las valoraciones morales.

Un tercer elemento de identificación de los cabarets estaba dado por la proclividad a atraer a individuos de distintas clases sociales, ${ }^{7}$ quienes disfrutaban de una diversión compartida que propiciaba -al menos de manera temporal-, la sensación de una comunión en el público asistente y cierta atenuación en la rigidez de la estratificación y separación social ordinaria. La situación descrita funcionaba como un estado de suspensión aunque su condición era relativa y efímera puesto que solo se sostenía en estados más o menos prolongados de entusiasmo y euforia, con la suficiente intensidad que posibilitara su aparición.

Momento en el que se abría de manera temporal un paréntesis en la estructura colectiva tradicional 
y se manifestaba el comportamiento anómalo e inesperado. Este espacio franco de la diversión nocturna era necesario para acceder a la distensión que no se obtenía mediante ninguna otra de las actividades diurnas. Sin embargo, a partir de la condición imprevisible, y hasta cierto punto fuera de control que se producía en el cabaret, este no podía tolerarse en cualquier parte de Guadalajara. En consecuencia, se optó por restringirlo a un sitio confinado y específico de la ciudad, y dado el estigma histórico vinculado a la zona de San Juan de Dios, esta fue constituida por decreto en el punto "natural" de las actividades y comportamientos fuera de la norma institucional, la cual generalmente responde a aquello que las clases social y económicamente hegemónicas prescriben como aceptable y decoroso, la cara socialmente presentable y factible de ser ostentada ante la otredad de la mirada externa.

\section{La coerción reglamentaria}

Las dependencias con mayor nivel de participación en el cumplimiento y sanción del reglamento correspondiente al funcionamiento de los cabarets, eran la Oficina de Inspección y Vigilancia de Reglamentos Municipales y la Tesorería Municipal, dependencias que operaban bajo las órdenes de la Secretaria del Ayuntamiento Municipal de Guadalajara. Mismas que operaban siguiendo una normatividad orientada a ejercer un control del negocio de cabaret, a partir de la implementación de medidas restrictivas -frecuentemente incumplidas- sobre dichos establecimientos, que tendía a limitar su exposición pública, en lo que subyacía la noción de que su oferta lúdica demeritaba la moralidad social. En esa condición se apoyaba el respaldo ético-ideológico de la restricción normativa de la libertad de acción de particulares en beneficio del presumible interés general de la colectividad (Villoro, 1992:280). Con base en ese recurso discursivo se prohibía a los cabarets que las autoridades municipales clasificaran como de segunda categoría su establecimiento en el primer cuadro de la ciudad. Y se reservaba esa ubicación para los de primera categoría, catalogados así con base en el capital que invertían en "muebles, enseres, instalaciones, ubicación, clase de servicio y promedio de ingresos brutos", por lo cual eran reconocidos por el Ayuntamiento como "centros turísticos" 8 . Por otra parte, antes de poder ofrecer al público sus servicios, el propietario estaba obligado a tramitar la licencia correspondiente en la Presidencia Municipal, para lo cual era necesario que estuviera libre de antecedentes penales y comprobara su honorabilidad y buen comportamiento. De igual modo, se negaba la posibilidad de que fueran propietarios de cabarets los funcionarios y empleados públicos, así como los extranjeros que residían de manera ilegal en el país?.

En lo referente a las condiciones materiales del cabaret, se debería cumplir con distintos requisitos, cubrir con las medidas sanitarias establecidas por los Servicios Coordinados de Salubridad y Asistencia Social y los de la Dirección de Obras Públicas. El negocio no debería tener ninguna vista directamente a la calle y el interior habría de estar oculto mediante cortinillas oscuras o mamparas, con una decoración decente y buena iluminación en el salón principal y no tener barra ni mostrador de cantina, estar ubicado a una distancia radial de 200 metros de centros educativos, nosocomios, hospicios, templos, cuarteles, fábricas y locales sindicales. El horario oficial de funcionamiento sería de las 21 p.m. a las 6 a.m. ${ }^{10}$ en el cual se podrían expedir bebidas embriagantes, a excepción del domingo en el que solamente se ofrecerían cervezas. En el caso de aquellos negocios que tuvieran la prerrogativa de haber sido declarados oficialmente como "centros turísticos", podrían funcionar de día y de noche, incluido el domingo, y expender licores sin ningún tipo de restricción. Cada cabaret tendría asignado un inspector o interventor nombrado por la Presidencia Municipal que sería pagado por el propio establecimiento, y se dispondría de la policía de servicio destacada en el lugar a fin de coadyuvar al cumplimiento de las disposiciones reglamentarias. Asimismo, se prohibía la presencia de mujeres que recibieran comisión por el consumo de los clientes y el acceso a menores de 18 años $^{11}$.

Un último aspecto sobresaliente de la reglamentación de los cabarets era la insistencia en que las variedades que presentaran deberían ser formativas y socialmente inocuas, por lo que se especificaba que las variedades deberían "contribuir al esparcimiento y buen gusto artístico, evitándose palabras obscenas o actos inmorales; quedando prohibido utilizarlas para ataques a la paz pública, a la vida privada de las personas, o para denigrar a las Instituciones"12.

Resulta muy significativo que las autoridades municipales pidieran que los espectáculos presentados al público no tuvieran contenidos moralmente perniciosos ni fueran sediciosos. 
Demanda comprensible dado que se trataba de espacios públicos no controlados directamente por el aparato de gobierno, en los cuales se tendía a hacer menciones sarcásticas o abiertamente críticas al desempeño de los funcionarios públicos ${ }^{13}$. Lo que hacía necesaria la coacción legal que inhibiera ese tipo de expresiones no deseables desde la lógica del orden de cosas socialmente dominante, caracterizado por la integración de distintas actividades realizadas por actores diferentes a partir de objetivos coincidentes (Goffman, 1991:92). Mismos, que en el caso que nos ocupa, se encontraban referidos, al menos discursivamente, a la salvaguarda de la moral social colocada como una premisa legítima y prioritaria, prioritaria sobre el interés particular -de orden lúdico- de los clientes de cabarets y la obtención de ganancias económicas por parte de sus administradores y trabajadores.

\section{Los claroscuros en la relación con la autoridad}

La actuación de los funcionarios públicos municipales respecto de la actividad de los cabarets incentivó en la opinión pública una percepción caracterizada por la ambigüedad y la desconfianza latente hacia las autoridades. En la cual se sustentó una relación que iba desde la solicitud de que se hiciera cumplir lo establecido por la reglamentación respecto de un caso específico, o el agradecimiento por el cumplimiento de la ley en términos de la clausura de establecimientos que se encontraban fuera de la normatividad, hasta a la apreciación y su consecuente denuncia respecto de la participación de miembros del ayuntamiento municipal en el giro de los cabarets o en contubernio con propietarios de ese tipo de negocios ${ }^{14}$. Esa percepción puede ser rastreada incluso en documentación oficial expedida por el ayuntamiento municipal. Este es el caso de un oficio fechado el 27 de septiembre de 1962 dirigido por Fernando Zárate Meneses, en su condición de Jefe de la Oficina de Inspección y Vigilancia de Reglamentos, al Lic. Eduardo Aviña Bátiz, Secretario del Ayuntamiento. En el documento se menciona que durante el recorrido de sobrevigilancia se detecto que a las $21.00 \mathrm{hs.}$, el "Restaurant California" 15 , ubicado en la Calzada 5 de febrero, se encontraba abierto al público con "infracción flagrante", y en su interior se encontraban 10 mujeres fichando y sirviendo "descaradamente" bebidas embriagantes a los clientes sin contar con la respectiva licencia para ello. En la relación se enfatizaba la siguiente agravante:

[...] la persona que atendía el servicio de cantina, en voz alta y delante de todos quienes estaban en la barra, expresó que ese negocio era de Juan Alatorre, y al llamarle la atención para que no se expresara de esa forma puesto que el señor Alatorre era Regidor del Ayuntamiento y no podía aparecer como propietario, respondió que no le importaba, pero que él sabía que era como lo decía ${ }^{16}$.

En esa misma línea de ideas, el 6 de febrero de 1964, el Dr. Juan Martínez Ortiz, con domicilio en la calle San Felipe \# 323, envió una carta al mismo Aviña Bátiz en la cual hacía mención de que su domicilio se encontraba cercano al "antro de vicio" de nombre "Jazz Club", por lo que era testigo de que el sitio era frecuentado por numerosos jóvenes estudiantes, tanto hombres como mujeres que acudían a ese sitio a consumir licor, con la consecuencia de que se suscitaban con frecuencia pleitos, gritos y borracheras, situación que resultaba muy molesta para los vecinos que habitaban en las inmediaciones a dicho negocio. Misma que no había sido corregida no obstante el perjuicio social que implicaba, lo que a su consideración respondía al hecho de que "su dueño tiene mucha influencia o palancas en el Ayuntamiento, lo que todos creemos, ya que de otra manera sería imposible que un lugar de tanto vicio estuviera situado tan cerca de una escuela y en lugar tan céntrico"17.

El Dr. Martínez terminaba su escrito solicitándole al funcionario que hiciera lo conducente para la clausura definitiva del establecimiento que había sido ya tan nocivo para la ciudad y la juventud de la misma, en lo cual se adhería a la petición que ya habían manifestado previamente un grupo de maestras en la columna Tribuna Libre del diario El Occidental del pasado 30 de enero.

Tres años más tarde, a través de esa misma publicación periódica, Jorge Ríos González, en su condición de miembro de la Junta de Mejoramiento Moral, Cívico y Material, manifestaba que una de las causas del fracaso de las campañas contra el fomento del vicio emprendidas por dicho organismo, era la tendencia que mostraban algunos funcionarios públicos a hacerse "de la vista gorda" a fin de dejar abiertos los establecimientos 
en donde se expedían bebidas embriagantes y mantener el flujo de recursos económicos para el erario. Así como de los "inspectores inmorales" tanto del Municipio, como de Salubridad y de Industria y Comercio, que recibían bonificaciones monetarias a cambio de no consignar las irregularidades y violaciones al reglamento. En esa misma situación se encontraban "policías venales" que extorsionaban a los propietarios a cambio de no denunciar la presencia en cabarets y cantinas de menores de edad o la venta ilegal de bebidas embriagantes. Asimismo, se denunciaba que los dueños de dichos establecimientos procuraban el "padrinazgo" de funcionarios influyentes sobornados mediante dadivas económicas, o que buscaban obtener influencia política o "quedar bien" con los propietarios que tenían recursos económicos considerables o cierta relevancia social. A la vez que Ríos González hacía notar que era "posible quedarse atónito al ver quienes son los que solicitan estos permisos con el objeto de revenderlos o manejarlos 'a tras mano""18. Es probable que dichos personajes pudieran encontrarse entre el sector de mayor prestigio social, los mismos que se abrogaban el derecho a determinar lo aceptable e inaceptable, e imponer su perspectiva axiológica del deber ser individual y colectivo, como verdad inobjetable, a partir de su nexo con los sistemas de poder encargados de producirla y mantenerla en su estatus de "régimen de verdad" (Foucault, 1992:189), sobre el que se determina la normatividad común sancionable moral y legalmente.

Más de una década después, en el curso de 1978, ante la permanencia de la problemática del vicio en la ciudad, la Federación de Sociedades de Padres de Familia, "ante la tibieza de algunas autoridades para erradicar lacras que causan perniciosa influencia en las nuevas generaciones", anunció la realización de un pacto con maestros estatales y federales para combatir el deterioro social. Al tiempo que se manifestaba que el presidente de dicha Federación, el Lic. Samuel Rivas Hernández, había acudido con anterioridad a felicitar al Jefe de la Oficina de Reglamentos del Ayuntamiento de Guadalajara, por la clausura de distintos antros de vicio, pero que posteriormente había tenido que presentar ante esa misma dependencia una queja formal debido a la tolerancia mostrada para la reapertura de los giros ya clausurados, e incluso, la expedición de nuevos permisos. Precisando que tenía pruebas y testimonios de que se habían reabierto 19 nuevos establecimientos en los que se expendían vinos, 7 hoteles de paso y 4 prostíbulos ${ }^{19}$.

En la relación entre la ciudadanía y el funcionario público, que nos revelan las fuentes descritas, es manifiesto el conocimiento que la ciudadanía tenía en relación con la participación clandestina de funcionarios públicos en los lucrativos negocios del cabaret, las cantinas y demás giros vinculados. Con todo, a pesar de la desconfianza hacia su desempeño, el funcionario mantenía su "legitimidad" a partir de las prerrogativas legales que avalaban su cargo público y el reglamento bajo su resguardo. Dos elementos con una fuerte carga simbólica reiterada y reforzada a partir de su persistencia y evolución histórica (Augé, 1998:84), misma que eventualmente le habría permitido al funcionario deshonesto no solamente ejercer su rol público de agente con capacidad de vigilar y sancionar las violaciones a la reglamentación, sino incluso, de trasgredir la propia norma de manera impune al amparo del poder derivado de sus prerrogativas institucionales.

\section{Poder y reconfiguración impositiva del espacio urbano}

Durante el período comprendido entre 1978 y 1983 se instrumentó a nivel nacional El Plan Nacional de Desarrollo Urbano, en el cual se concentraban las principales directrices en materia de ordenamiento territorial, mediante distintos programas de acción plurisectorial, a la vez que se buscaba integrar a las distintas localidades al sistema nacional urbano. Dicha planeación carecía de una valoración de las repercusiones sociales que implicaría su aplicación, de las diferencias históricas de cada núcleo poblacional, inflexibilidad en sus propuestas, contradicciones entre intereses regionales particulares y una definición tardía de las políticas de uso de suelo. Como derivación de dicha política nacional, en la ciudad de Guadalajara, en su condición de capital del Estado de Jalisco, empezaron a darse a conocer planes parciales de desarrollo tendientes a concretar la consolidación, regulación y control del crecimiento urbano. En ese contexto, en 1978, dio inicio el proyecto de creación del Centro Metropolitano, conocido en la actualidad como Plaza Tapatía, en la que se unirían las dos Guadalajara a través de una serie de Plazas y espacios abiertos arbolados, teniendo como eje conector a San Juan de Dios. El proyecto implicó 
la expropiación y demolición de todas las manzanas comprendidas en el polígono afectado por dichas obras y la demolición del Coliseo Olímpico y la Plaza de Toros El Progreso, paradójicamente sacrificada precisamente en aras de un pretendido progreso urbanístico. La iniciativa se sustentó a partir de un discurso que ponía de relieve el bien común, la modernidad y el progreso, pero que de facto propició una mayor segregación social y alteración de la vida urbana. En una dinámica posibilitada por la conjugación de una acción centralista y la alianza de las élites económicas y políticas locales, interesadas en adecuar la configuración del espacio urbano de acuerdo con sus propios intereses y perspectivas (Gómez Sustaita, op. cit.:205; García, 1992:171-174).

Este radical cambio urbano fue un reflejo del poder fáctico de la minoría gobernante y el sector socialmente influyente. Guadalajara, la ciudad partida en dos, tenía en la población del Poniente un peso específico muy superior al existente en el Oriente, en un claro desequilibrio de fuerzas que permitió la imposición unilateral de un proyecto ideado desde el gabinete, al margen del consenso y la procuración de un efectivo beneficio colectivo.

Esa línea de pensamiento y de acción, se vio confirmada en 1982, con la publicación del nuevo Código Penal del Estado de Jalisco, promovido por el gobernador Flavio Romero de Velasco, en el que se prohibía el lenocinio en la entidad, delito que se castigaría de 5 a 9 años de prisión y como multa el equivalente de 500 a 2000 días de salario. Asimismo, se prohibía la administración de prostíbulos en cualquiera de sus expresiones. Se estipulaba que realizaba una actividad de lenocinio el individuo que se encontrara en cualquiera de los siguientes casos,

"I. Explote el cuerpo ajeno por medio del comercio carnal, se mantenga de este comercio u obtenga de él un lucro cualquiera; II. Induzca, promueva, facilite, medie, consiga, entregue o solicite a una persona para que con otra comercie sexualmente con su cuerpo o le facilite los medios para que se entregue a la prostitución; y

III. Regente, administre o sostenga prostíbulos, casas de cita o lugares de concurrencia donde se explote la prostitución u obtenga cualquier beneficio con sus productos" 20 .
A derivación de la nueva disposición reglamentaria se produjo el cierre de los cabarets de la zona de San Juan de Dios. En ello, un primer hecho significativo estuvo dado por el hecho de que este fue el único sitio en el que se aplicaron con total rigor las nuevas disposiciones legales (Ramos, op. cit.:146). En segunda instancia, esa aplicación selectiva exhibía el hecho de que si bien, en principio, la ley obligaba a todos, en términos prácticos no estaba concebida ni creada pensando en la colectividad, sino en las clases más numerosas y con menor nivel educativo (Foucault, 2002:167). El viejo barrio de San Juan de Dios siempre había sido motivo de censura y disgusto, ubicado como punto de concentración de todo tipo de actividades ilegales y de delincuencia, situaciones que debían ser controladas lo más posible para disminuir lo inquietante de su presencia, considerada "perpetuamente amenazadora para la vida cotidiana" (Foucault, op. cit.:175). Así, se consideró que la mejor forma de ejercer dicho control era revocando la misma base legal a partir de la que se le había asignado a San Juan de Dios en 1895, la función de zona roja de la ciudad. Prohibiéndose la realización de las actividades que anteriormente se le habían asignado de manera oficial, en un bimbalete legal que respondió en cada uno de sus vaivenes a la voluntad política del gobernante en turno que los promovió, en alianza con la clase social dominante, la "gente conocida" y, por ende, reconocida como interlocutora legítima, al margen de la participación de quienes se vieron directamente afectados por las modificaciones realizadas.

Este sector de la población fue sometido al rol de actor pasivo, al silencio, y a la exclusión, siendo estigmatizado por la ideología dominante con una reputación negativa ${ }^{21}$ que de manera implícita los ubicaba en una posición de inferioridad moral, en adición a su condición económica desfavorable. Ese acto de segregación y selección no natural y sí socialmente determinado, fue particularmente notorio en la integración de las comisiones y grupos colegiados instituidos para la toma de las decisiones relacionadas con la nueva configuración urbana (González, op. cit.:145).

A partir de la falta de consenso derivado del comportamiento clasista, se invalidaba la legitimidad de las obras desde la perspectiva de un bienestar común fehaciente e inobjetable. En esas condiciones, lo único que quedaba era la "validación" discursiva amparada en las prescripciones legales, 
recurso que apenas podía disimular la naturaleza imparcial e inflexible de las decisiones tomadas, reflejo de un ejercicio de la autoridad desarrollado de espaldas a la ciudadanía. Más específicamente, de un cierto sector de la ciudadanía que en última instancia resultaba sacrificable dado su estatus marginal, en una organización social que en la práctica distinguía entre ciudadanos de primera y de segunda, y actuaba en consecuencia a partir de distintos parámetros que orientaban su relación con unos y otros.

\section{Conclusiones}

El presente escrito constituye un primer acercamiento analítico a un tópico clave para dirigir la reflexión sobre una de las actividades de mayor relevancia y pertinencia para la comprensión del acto lúdico considerado este, como una parte seminal de la interacción humana en la ciudad de Guadalajara. En un sistema social en el que destaca la ambigüedad presente en la acción prescriptiva y punible exhibida por la autoridad pública, al ser objeto de acusaciones de corrupción, y mostrar serias inconsistencias en la aplicación de la normatividad que ponen en entredicho su legitimidad y solvencia moral.

Por otra parte, tradicionalmente la sociedad tapatía ha sido identificada en lo general por su conservadurismo, de manera que, en principio, todo indicaría que la actividad del cabaret, con toda la negativa carga simbólica asociada a este tipo de ámbitos, no tendría en la ciudad un terreno fértil para desenvolverse, y es precisamente a partir de esa condición desfavorable que resulta indicativa la manifestación de una actividad lúdica de la intensidad generada en torno a los cabarets, punto de referencia del entretenimiento citadino. Esta situación denota la resonancia del tiempo destinado a la recreación festiva como parte fundamental del tejido social, particularmente si esta se presenta en un entorno represivo como es el característico de las comunidades de tenencia conservadora. En esas condiciones pareciera que se favorece la aparición de microcosmos urbanos sui generis con ambientes que permitan aliviar, hasta cierto punto, la rigidez de las relaciones sociales y el control normativo. Este fue el caso del cabaret tapatío, en este espacio el individuo tendía a manifestar una acción transparente, típicamente más libre y espontánea, en donde el orden de cosas habitual daba paso a un estado de suspensión temporal a partir de la vivencia festiva compartida.

El barrio de San Juan de Dios, debido a su condición como territorio neurálgico de buena parte de las ofertas de diversión locales, funcionó como termómetro de los cambios en la reglamentación oficial decretada para la administración pública de ese tipo de actividades. La nominación de esta territorialidad urbana como zona roja, confirma la manera en que la ideología dominante ha concebido a este lugar -y en derivación, a quienes lo habitan-, tomando en cuenta que se trata de una metáfora construida a partir del color rojo, al que normalmente se asocia la idea de peligro e inseguridad. En consecuencia, devino de manera simbólica y fáctica, en un ámbito distinto del resto de la ciudad, que formaba y no formaba parte a la vez de la misma. Ello, por su propia historia de ocupaciones inclinadas hacia los márgenes de la legalidad, ante la procuración de la sobrevivencia en un entramado citadino con flujos migratorios que incidían en la elevación del desempleo y la pobreza. Pero también por la mirada externa censora de la "gente conocida" y de las autoridades formalmente establecidas, al tiempo que se producían abusos de funcionarios públicos en connivencia con quienes infringían la normatividad, en un doble discurso que permitió manipular a conveniencia el discurso de la moral pública, haciendo recaer la atención sobre el otro, el distinto. Sobre el que se proyectaba una imagen de referencia de lo socialmente indeseable y anormal que lo convertía en el objeto "natural" de la reprobación y estigmatización social. Sobre esta base se articuló el cuerpo ideológico en el que se intentaron justificar las medidas de control ejercidas sobre la acción de los cabarets y que finalmente tuvieron como corolario la aplicación normativa parcialmente dirigida, congruente con la visión hegemónica históricamente exhibida en un acto de fuerza que no requirió de la adhesión de voluntades para concretarse.

En el plano teórico la legitimidad de la actuación de todo poder público se apoya en el consenso y la equidad, que le confieren autoridad para la aplicación de la reglamentación común al cuerpo social. A partir de esa premisa, la desaparición forzada de buen número de cabarets tapatíos constituyó una disposición parcial e inconsistente, que restringió la utilidad colectiva del paradigma legal y recrudeció su connotación de instrumento opresivo del aparato de gobierno, al margen de las libertades 
y derechos civiles que debería garantizar. En ese punto se dejaron de lado la razón y la justicia como fundamentos de la interacción entre gobernantes y gobernados, no obstante ser elementos esenciales de la interacción humana socialmente organizada, en cuya ausencia la vida en sociedad se vuelve equiparable a cualquier otro ecosistema biótico regido por la imposición del más fuerte.

\section{Referencias Citadas}

Arroyo Alejandre, Jesús (et al.)

1986 Migración a centros urbanos en una región de fuerte migración, El caso del occidente de México. Universidad de Guadalajara, Guadalajara, Jal.

Augé, Marc

2000 Los no lugares, Espacios del anonimato. Una antropología de la sobremodernidad, Editorial Gedisa, Barcelona. 1998 Hacia una antropología de los mundos contemporáneos, Editorial Gedisa, Barcelona.

Bourdieu, Pierre

2007 El sentido práctico. Siglo Veintiuno Editores, Buenos Aires.

Crozier, Michel y Erhard Friedberg

1990 El actor y el sistema. Las restricciones de la acción colectiva, Alianza Editorial Mexicana, México.

Durkheim, Emile

2000 Las reglas del método sociológico, Ediciones Quinto Sol, México.

Foucault, Michel

2002 Vigilar y castigar: nacimiento de la prisión, Siglo Veintiuno Editores, Argentina.

1992 Microfísica del poder, Ediciones Endimión, Madrid.

García Rojas, Irma Beatriz

1992 "Dos ciclos de planeación urbana en Guadalajara" en Castañeda, C. (coord.), Vivir en Guadalajara. Ayuntamiento de Guadalajara, Guadalajara, Jal., pp. 161-176.

Goffman, Erving

1991 Los momentos y sus hombres, Ediciones Paidos, Barcelona.

Gómez Sustaita, Guillermo y Juan Gil Flores

2008 Barrios tradicionales de Guadalajara, Barrio de San Juan de Dios, Gobierno Municipal de Guadalajara, Guadalajara, Jal.

Gómez Sustaita, Guillermo

2002 El siglo XX. Los decenios de Guadalajara. Instituto Cultural Ignacio Dávila Garibi, Guadalajara, Jal.

González Romero, Daniel

1988 Jalisco desde la revolución. Arquitectura y desarrollo urbano, T. X., Gobierno del Estado de Jalisco: Universidad de Guadalajara, Guadalajara, Jal.

Gramsci, Antonio

2002 La política y el estado moderno, Colección Fontamara, México.
Huizinga, Johan

1943 Homo ludens. El juego y la cultura, Fondo de Cultura Económica, México.

Medina, Dante

1999 Los placeres de los ojos, Gobierno del Estado de Jalisco, Guadalajara, Jal.

Ramírez Sáiz, Juan M. y Patricia Safa Barraza

2009 "Tendencias y retos recientes en tres metrópolis mexicanas: Ciudad de México, Guadalajara y Monterrey" en Lacarrieu, M. (et al.). Antropología de las ciudades. La "nueva cuestión cultural" y la cuestión social en declive en las urbes contemporáneas, Facultad de Filosofía y Letras: Universidad de Buenos Aires, Argentina, pp. 77-92.

Ramos Willchis, Víctor Manuel

2005 "Los cabaretes de Guadalajara" en González, L.A. (coord.), Encuentros sociales y diversiones, Secretaría de Cultura del Estado de Jalisco, Guadalajara, Jal., pp. 125-137.

Signorelli, Amalia

1999 Antropología urbana, Antropos: Barcelona; Universidad Autónoma Metropolitana: México.

Trujillo Bretón, Jorge Alberto

2002 "El vicio, el crimen y los "bajos fondos" porfirianos, Guadalajara 1877-1911” en Trujillo, J.A. y De la Torre, F., Seminario de Estudios Regionales, Anuario 2002, Tepatitlán, Jal., pp. 61-76.

Vázquez, Daniel

1992 "La urbanización de Guadalajara", en: Rendón García, Lina (coord.), Capítulos de historia de la ciudad de Guadalajara, T. I, Ayuntamiento de Guadalajara, Guadalajara, Jal., pp. 38-70.

1985 "La ciudad en perspectiva", en Guadalajara, la gran ciudad de la pequeña industria, Arias, Patricia (coord.), El Colegio de Michoacán, Zamora, Mich., pp. 57-76.

Villoro, Luis

1992 Creer, saber, conocer, Siglo Veintiuno Editores, México. Vizcarra Dávila, Miguel

2009 "Uso del cuerpo y empoderamiento: 'teiboleras' al ataque" en Estudios Jaliscienses, El Colegio de Jalisco, $\mathrm{N}^{\mathrm{o}}$ 76, Zapopan, Jal., pp. 28-39.

Zizek, Slavoj

1988 "Acerca del poder político y de los mecanismos ideológicos" en Cuicuilco, Revista de la Escuela Nacional de Antropología e Historia, México, pp. 113-125.

\section{Notas}

1 Este documento está vinculado a una investigación más amplia sobre los rasgos sociales, culturales, políticos y económicos que definieron el particular microcosmos urbano generado en torno a los cabarets en la ciudad de Guadalajara.
2 Como cabaret se entenderá: "todo centro de reunión y esparcimiento social que tenga orquesta permanente, espacio amplio para bailar, servicio de restaurante y en donde se organicen manifestaciones artísticas" (Reglamento 
de espectáculos públicos aprobado por el Ayuntamiento Constitucional de Guadalajara el 14 de agosto de 1949: p. 40. Archivo Municipal de Guadalajara).

Se utilizará exclusivamente la palabra cabaret sin hacer uso del término centro nocturno como sinónimo para evitar confusiones, en atención a que en el lapso de estudio se les llamaba también centro nocturno a escuelas para adultos que funcionaban en un horario nocturno (José Escobar Jiménez, cliente de cabarets, entrevista realizada el 04/08/2010).

3 Fausto Meza López, cliente de cabarets, entrevista realizada el 16/11/2010.

Desde una perspectiva normativa los establecimientos que únicamente tenían rockola no se incluían en la designación oficial existente para los cabarets descrita en la nota anterior, debido a que no contaban con variedad, una orquesta permanente, o servicio de restaurant, sin embargo, sí contaban con una pista de baile y la apreciada oferta de compañía femenina, lo que, de acuerdo a mi informante, los hacía que fueran ubicados popularmente como cabarets.

4 En este punto retomo la propuesta heurística definida por Marc Augé en el sentido de que "el mundo moderno se presta a la observación etnológica, con la sola condición de poder aislar en él unidades de observación que nuestros métodos de investigación sean capaces de manejar" (2000:19, 20).

5 Fausto Meza López, entrevista citada.

6 Dato tomado de la revisión de los anuncios promocionales presentados durante las décadas de los sesenta y setenta en El Informador y El Occidental.

7 Esta afirmación es válida sobre todo en el caso del contacto que se producía entre la clase media y la proletaria en los cabarets denominados de segunda categoría, mientras que la "sociedad acomodada" acudía a cabarets considerados como "centros sociales de primer orden" (Acta de la Sesión del Cabildo Municipal de Guadalajara del 10 de diciembre de 1945, Fojas 383 y 384: Archivo Municipal de Guadalajara).

8 Reglamento de espectáculos públicos aprobado por el Ayuntamiento Constitucional de Guadalajara el 14 de agosto de 1949: p. 40, 42. Archivo Municipal de Guadalajara.

9 Reglamento de espectáculos públicos aprobado por el Ayuntamiento Constitucional de Guadalajara el 14 de agosto de 1949: p. 41. Archivo Municipal de Guadalajara.

10 De acuerdo con el testimonio de mi informante Fausto Meza López, no era raro que se incumpliera dicha estipulación sobre el horario.

11 Reglamento de espectáculos públicos aprobado por el Ayuntamiento Constitucional de Guadalajara el 14 de agosto de 1949: p. 41-45. Archivo Municipal de Guadalajara.
12 Reglamento de espectáculos públicos aprobado por el Ayuntamiento Constitucional de Guadalajara el 14 de agosto de 1949: p.43. Archivo Municipal de Guadalajara.

13 Acción que corresponde a una subversión que se ubica en el kinismo, es decir, la crítica popular a la cultura oficial mediante la ironía y el sarcasmo que tienen la intención de ridiculizar a la ideología dominante, y evidenciar los intereses egoístas y la búsqueda de poder que subyacen ocultos en sus enunciados ideológicos (Zizek, 1988:114).

14 Este planteamiento lo sustentó a partir de la revisión de las Actas del Cabildo Municipal correspondientes a las décadas de los sesenta y setenta.

15 Al margen de su designación formal, en realidad se trataba de un lugar en el que se consumían bebidas alcohólicas, había presentación de artistas y pista para bailar, lo que para efectos prácticos lo ubicaba más propiamente como un cabaret, como el propietario optaba por tramitar la licencia del establecimiento como restaurante dado que seguramente la licencia de cabaret sería más difícil de obtener y tendría un mayor costo.

16 Oficio 030. Informe de sobrevigilancia. Oficina de Inspección y Vigilancia de Reglamentos del Ayuntamiento de Guadalajara. 27 de septiembre de 1962, fojas 1,2. Archivo Municipal de Guadalajara.

17 Carta enviada por el Dr. Juan Martínez Ortiz al Lic. Eduardo Aviña Bátiz, Secretario del Ayuntamiento de Guadalajara, del 6 de febrero de 1964, localizada en el libro de actas del cabildo municipal. Archivo Municipal de Guadalajara.

18 El Occidental. "Hoy urge terminar con el vicio", 17 de mayo de 1967, Sección B, pp: 1, 3. Este diario se ha caracterizado por mantener en sus artículos periodísticos un mayor nivel de crítica y de denuncia, respecto de las inconsistencias del ejercicio público a nivel local y regional, a diferencia de su homologo El Informador, en el que por lo general se maneja de forma más o menos velada una postura más afín con el discurso y la práctica de las autoridades institucionales.

19 El Occidental. "Protesta contra el vicio. Maestros y padres de familia han firmado un pacto", 7 de mayo de 1978, Sección B, p. 1.

20 Código Penal para El Estado Libre y Soberano del Estado de Jalisco, publicado el 2 de septiembre de 1982 en el Periódico Oficial del Estado de Jalisco.

21 En lo cual entra en juego un componente de subjetividad a partir del que se define comúnmente la identidad y la alteridad en el espacio social, de ahí que "los individuos o los grupos son definidos no solamente por lo que son, sino también por lo que tienen la reputación de ser" (Bourdieu, 2007: 217). 
